\section{Assistência multiprofissional à vítima de violência sexual: a experiência da Universidade Federal de São Paulo}

\author{
Multidisciplinary care for victims of sexual \\ assault: the experience at the Federal \\ University in São Paulo, Brazil
}

\author{
${ }^{1}$ Casa de Saúde da Mulher \\ Professor Domingos Deláscio, \\ Universidade Federal de \\ São Paulo, São Paulo, Brasil. \\ Correspondência \\ R. Mattar \\ Casa de Saúde da Mulher \\ Professor Domingos \\ Deláscio, Departamento \\ de Tocoginecologia \\ Universidade Federal de \\ São Paulo. \\ Rua Napoleão de Barros 715, \\ 80 andar, São Paulo, SP \\ 04024-002, Brasil. \\ rosiane.toco@epm.br
}

\begin{abstract}
This article discusses the importance of multidisciplinary care for victims of sexual assault in order to mitigate the respective physical, psychological, and social harm. The article begins with a brief description of the activities by various professionals involved in the care of victims treated at the Women's Health Center of the Federal University in São Paulo, and presents the outcome of some cases treated at this institution in its five years of experience. The article provides the socio-demographic profile of female rape victims since the beginning of this women's health service, with the number of women who became pregnant, those who underwent abortion, and the number of court suits filed.
\end{abstract}

Sexual Assault; Rape; Violence Against Women; Assistance
Rosiane Mattar 1

Anelise Riedel Abrahão 1

Jorge Andalaft Neto 1

Osmar R. Colas 1

Irene Schroeder 1

Salvina Jesus Reis Machado 1

Silvana Mancini 1

Beatriz de Aguiar Vieira 1

Georgia Bianca Martins Bertolani 1

\section{Introdução}

Este artigo tem como objetivo discutir a importância da assistência multiprofissional às vítimas da violência sexual para redução dos agravos físicos, psíquicos e sociais que podem advir desta violência. Para tanto se faz uma breve descrição das atividades realizadas pelos diferentes profissionais que prestam assistência na Casa da Saúde da Mulher Professor Domingos Deláscio da Universidade Federal de São Paulo (UNIFESP), e são apresentados alguns dos resultados deste trabalho nos seus cinco anos de existência.

A criação da Casa da Mulher, em 1998, foi uma resposta à solicitação do governo e da sociedade civil para que os cursos universitários da área de saúde incluíssem em seu currículo questões sobre assistência às mulheres vítimas de violência sexual.

Dessa forma, a organização do serviço buscou, simultaneamente, garantir um atendimento humanizado e de qualidade às mulheres $\mathrm{e}$ constituir-se em um espaço de aprendizagens múltiplas, ensinando aos alunos a fazerem diagnósticos e instituírem terapêuticas corretas, aproximando-os e sensibilizando-os para a problemática envolvida na violência sexual, e estimulando-os para o trabalho coletivo, a partir do diálogo com colegas de formações distintas da sua. Entende-se que esse aprendizado possibilita que, no decurso da sua vida profissional, qualquer que seja a inserção de trabalho, estes jovens 
estejam capacitados a prestar assistência às vítimas de violência sexual e motivados a tratá-las com respeito. É também uma das estratégias de trabalho da Casa da Mulher a realização de atividades voltadas para a capacitação e sensibilização dos demais docentes, discentes e funcionários da UNIFESP, como modo de disseminar os procedimentos corretos para o atendimento destes casos e ampliar a discussão sobre o tema da violência sexual na sociedade.

\section{Violência sexual}

A necessidade da abordagem multiprofissional no atendimento de mulheres que sofrem violência sexual está diretamente relacionada à complexidade da situação e à multiplicidade de conseqüências impostas às vítimas ${ }^{1,2}$. Esse tipo de violência pode implicar a ocorrência de problemas de saúde física, reprodutiva e mental, como lesões corporais, gestação indesejada, DST e AIDS, fobias, pânico, síndrome do stress pós-traumático, depressão e outras alterações psicológicas, e também de problemas familiares e sociais, como abandono dos estudos, perda de empregos, separações conjugais, abandono de casa, e outros. A violência sexual também acarreta a procura mais freqüente dos serviços de saúde, por queixas vagas, variadas ou de repetição ${ }^{3}$.

Quando a violência sexual ocorre com meninas, dentre as suas conseqüências devem ser considerados também os problemas escolares. Segundo Herbst et al. 4, 46,1\% das jovens prépúberes abusadas sexualmente apresentavam dificuldades na escola, seja de aprendizagem, de comportamento, de relacionamento ou de ambos; e que $45,7 \%$ das violências praticadas no âmbito familiar estavam ligadas ao uso de álcool, drogas e prostituição.

Hampton 5, estudando mulheres adultas, verificou que $5 \%$ das vítimas apresentaram traumas físicos maiores, necessitando internação hospitalar, e 1\% traumas genitais graves; além disso, $7 \%$ das mortes violentas de mulheres eram acompanhadas de violência sexual.

Estima-se um percentual de gravidez após violência sexual entre $0,5 \%$ a $1-3 \% 6$, problema que reveste de uma gama enorme de implicações, como o risco de abortamentos clandestinos, com conseqüências físicas variáveis desde processos anêmicos e infecciosos até perda de órgão ou óbito materno, e risco gestacional como complicações na gravidez, prematuridade, óbito fetal, anóxia perinatal, abandono de recém-nascidos, infecção puerperal e outras.

Quanto à AIDS, Hampton 5 sugere que o risco de infecção pelo HIV é menor que $1 \%$. Gostin et al. 6 o relataram em torno de $2 / 1.000$, quando o contato é só pênis-vagina. Para as demais DST, Jenny et al. 7 apuraram vaginose bacteriana em $19,5 \%$ e gonorréia em $4,2 \%$.

Em relação aos aspectos emocionais são freqüentes os sentimentos de medo da morte, sensação de solidão, vergonha e culpa 8 , e o surgimento de graus variáveis da síndrome do estresse pós-traumático, que pode acarretar conseqüências imediatas e tardias, como fobia, pânico e depressão.

Aspectos sociais como abandono de escola, emprego, separações, abandono de lar, prostituição etc., fazem parte dos problemas psicossociais envolvidos com a violência sexual 9 .

As vítimas de violência, muitas vezes ficam constrangidas ou aterrorizadas em realizar os procedimentos legais que poderiam determinar punição ao agressor. Assim, na maioria dos casos de violência sexual/sanitarista, as mulheres, sem orientação de um advogado, não iniciam procedimentos nas delegacias que iriam abrir inquérito e determinar julgamento e castigo aos agressores. Por isso é importante que a equipe conte com profissional da área do direito. Do mesmo modo, se da agressão resulta uma gravidez, é necessário um adequado suporte psicológico para facilitar para a mulher a tomada de decisão em relação a esta gestação.

\section{Atividades da equipe multiprofissional}

Considerando a importância de uma abordagem ampla e integrada às mulheres que sofreram violência sexual, a equipe Casa da Mulher é constituída por médicos tocoginecologistas, enfermeiras, psicólogas, psiquiatra, assistente social, socióloga/sanitarista e advogado. A partir dos profissionais que formam a sua equipe, a Casa da Mulher estabelece interfaces com os departamentos de Tocoginecologia, Medicina Preventiva, Psicobiologia e com a Escola de Enfermagem.

O protocolo de atendimentos tem como pressuposto a assistência personalizada, ou seja, os mesmos profissionais que atendem a mulher na primeira consultam acompanham o caso até o seu desfecho, seja qual for. Isso é particularmente importante quando se trata do atendimento médico, pois o médico residente de tocoginecologia que atende a paciente na primeira consulta médica a acompanha durante as outras consultas, internação e eventual interrupção da gestação. Essa personalização do atendimento médico traz para a mulher maior segurança e tranqüilidade, em especial quando ocorre uma gravidez. É também uma oportunidade de aproximação do jovem profissional com os aspectos sociais 
e emocionais da violência sexual e do aborto, possibilitando aprendizado prático de questões relativas à integralidade e humanização do atendimento 10 .

Segue-se uma breve descrição do trajeto da mulher quando ela entra no serviço:

- O primeiro contato com a Casa da Mulher é feito com o atendimento pela equipe de enfermagem: são estas profissionais que acolhem a paciente no ambulatório, procurando estabelecer relacionamento que garanta sua aderência ao serviço. A equipe de enfermagem é responsável por realizar a anamnese, providenciar os exames laboratoriais, orientar a utilização das medicações, agendarem consultas com os outros profissionais, acompanhá-la em exames especiais e durante os procedimentos necessários.

Realizam o armazenamento e coleta de dados de informações pessoais, antecedentes de saúde geral, ginecológica e obstétrica, tipo de violência, características do agressor e as condutas tomadas no serviço. Ao final desta primeira consulta a usuária é agendada para atendimento médico, psicológico, do serviço social e com o setor jurídico, buscando-se concentrar estas consultas num mesmo dia, sempre que possível, e garantindo-se que ocorram com o menor intervalo de tempo possível a partir da chegada da mulher ao serviço.

- Atendimento médico. No atendimento médico realizado imediatamente após a violência, seguem-se os procedimentos preconizados pelo Ministério da Saúde 11: tratar as lesões que, porventura tenham acontecido; verificar a presença de DST, solicitando os exames laboratoriais; colher material para possível identificação do agressor e prescrever medicamentos para a profilaxia de gestação e DST. Durante o seguimento ambulatorial a equipe médica realiza as seguintes intervenções: repetir reações sorológicas para identificação de DST até seis meses após o evento; realizar citologia oncótica pelo risco de aquisição de papilomavírus; e proceder ao controle das funções hepáticas, renais, hematológicas etc., pelo uso dos anti-retrovirais.

A equipe médica também é responsável por efetuar a interrupção da gestação quando for solicitado pela paciente em tempo hábil.

- Atendimento psicológico. As psicólogas são responsáveis pela avaliação e diagnóstico do quadro psicológico da vítima de violência sexual e propõem o esquema de tratamento.

$\mathrm{Na}$ maioria das vezes, as mulheres que procuram o serviço são atendidas no modelo de psicoterapia breve, que visa a avaliar os sentimentos predominantes, o nível de estresse pós-traumático, a desorganização da vida pessoal e reações psicossomáticas. Durante o acompanhamento psicoterapêutico é verificado como se dá o retorno ao trabalho ou à escola, e trabalha-se para diminuir sentimentos persecutórios, baixa auto-estima e possíveis dificuldades em relação à figura do homem ${ }^{2}$.

Quando a paciente procura o serviço já sabendo estar grávida em decorrência do estupro, são abordados sentimentos relacionados à constatação da gestação e avaliados os princípios morais e religiosos que possam interferir na decisão pela interrupção ou não da mesma. As fantasias quanto à gravidez e ao abortamento também são elucidadas.

Em casos de interrupção da gravidez, a mulher recebe acompanhamento psicológico durante toda a internação hospitalar para a realização do abortamento. Também se oferece às pacientes, assistência durante e após o procedimento.

As que decidem manter a gestação são acompanhadas durante o pré-natal, com assistência particularizada àquelas que optam por entregar o recém-nascido para adoção.

A equipe conta com retaguarda psiquiátrica para avaliação dos casos mais graves e eventual suporte medicamentoso.

- Atendimento por socióloga. Visa a dar suporte aos familiares e parceiros das vítimas de violência sexual, uma vez que a desestruturação social é importante nestes casos e pode se constituir no agravamento da violência já sofrida pela mulher. É responsável também pelos grupos de socialização das mulheres, depois que elas passam pelas sessões de psicologia. Nesses grupos se discute as dificuldades trazidas pelas mulheres, no processo de ressocialização, seja no mundo do trabalho, no mundo afetivo, nas relações de amizades e familiares.

- Atendimento por assistente social. É feita entrevista individual visando a conhecer a história da vida da paciente e traçar seu perfil sócioeconômico. Esta abordagem visa a minimizar as dificuldades que possam interferir na aderência ao serviço, nas decisões a serem tomadas relativas à violência, a uma eventual gestação e à retomada do cotidiano, além de orientar em relação a documentos, transporte, contatos com família e trabalho. Também é feito contato com outras entidades, visando a auxiliar a mulher na busca de abrigo, quando a violência sexual se dá no contexto doméstico.

Nos casos de gestação em que a mulher resolve doar a criança, a assistente social pode intermediar o processo junto à Vara da Família.

- Atendimento por advogado. O aconselhamento jurídico é vital no combate à impunidade das vítimas. Para cumprir este papel o Instituto Pro Bono de assistência jurídica fez parceria 
com a UNIFESP para assessorar gratuitamente as mulheres que recebem tratamento na Casa da Mulher.

Tal assessoria abrange desde orientações quanto à lavratura do boletim de ocorrência, como o acompanhamento nas fases de investigação, de inquérito policial e ação penal. Alguns processos contra agressores que foram identificados encontram-se em fase bem adiantada.

Pela visão da lei, da justiça e da polícia, as vítimas de violência sexual, muitas vezes, são julgadas e devem provar que são vítimas reais, além de precisarem arcar com o ônus da prova. Pelo lado da mulher, a vergonha e o trauma contribuem para reforçar as dificuldades de comprovação da violência sofrida. Nesta procura por provas que não só o relato da vítima, o profissional do direito encoraja e auxilia essas mulheres.

A equipe interdisciplinar reúne-se semanalmente para discussão dos casos, garantindo a sincronia no atendimento e permitindo uma visão integral e única de todos os profissionais sobre cada paciente atendida. Essa dinâmica de trabalho possibilita atualizar a visão de cada profissional sobre a violência, e ao mesmo tempo assegura maior qualidade na assistência às vítimas.

Essa é uma reunião aberta onde participam, além da equipe profissional, os alunos de graduação em medicina e enfermagem, de pós-graduação e residentes, que assim fazem a sua formação inseridos no trabalho interdisciplinar como forma de assistência na área da saúde.

\section{Um retrato dos atendimentos}

Nos últimos cinco anos foram atendidas 366 vítimas de violência sexual na Casa da Mulher, sendo $50 \%$ adolescentes e $3 \%$ menores de 15 anos, procedentes de São Paulo capital. A maioria é católica, branca, solteira, reside com os pais (50\%) e freqüentaram escola até o ensino médio (55\%). Metade refere renda familiar de até dois salários mínimos e 5\% delas relatam renda acima de seis salários mínimos.

O estupro foi referido em $95 \%$ dos casos, tendo ocorrido na residência (45\%), na rua (45\%) e na casa do agressor (5\%). Em 40\% dos casos havia história anterior de algum tipo de violência com o mesmo agressor.

Em $45 \%$ o ato de violência foi praticado por desconhecidos e o restante (55\%) por familiares (pais, tios, irmãos, cunhados), amigos ou namorados.

Em 30\% dos casos houve gestação e em 63\% delas ocorreu interrupção. Nos casos em que a gravidez evoluiu, $75 \%$ dos recém-nascidos foram para adoção e $25 \%$ ficaram com as mães.

Houve adesão de $75 \%$ das mulheres aos procedimentos propostos pelo serviço. Dentre as que continuaram o tratamento, a metade alegou não desejar um tratamento específico.

A partir da parceria Instituto Pro Bono/Escola Paulista de Medicina, 149 mulheres receberam atendimento jurídico, do acompanhamento das vítimas à delegacia até os casos que percorreram a ação penal e foram sentenciados. Até o momento, três agressores foram aprisionados pela violência que praticaram.

Segundo relato da maioria das mulheres atendidas, a primeira iniciativa após o ato de violência foi a busca de isolamento. Isso reforça a importância do suporte psicológico e do serviço social para que as mulheres possam romper com o silêncio e reorganizar as suas vidas após o evento traumático.

\section{A formação profissional}

A cada ano passam pela Casa da Mulher trinta residentes de Tocoginecologia, sendo que dez residentes do terceiro ano são os que prestam assistência personalizada às mulheres vítimas de violência sexual. Essa vivência tem se mostrado valiosa no sentido de sensibilizar médicos no início de suas atividades profissionais.

Aulas sobre o tema e discussões de casos são dirigidas a todos os alunos no quarto e sexto anos médico, sendo que para estes são ministradas aulas mensais a grupos de 14 alunos, o que torna o assunto mais próximo dos estudantes. Desse modo, qualquer que seja a especialidade que venham a exercer, esses alunos estão capacitados a prestar assistência às mulheres vítimas de violência sexual, até que possam ser recebidas em serviços especializados.

O estágio na Casa da Mulher é também uma atividade do currículo de enfermagem e medicina preventiva, possibilitando que oitenta alunas por ano passem pelo serviço, auxiliando no atendimento.

É função da UNIFESP promover pesquisa e divulgar seus resultados, de modo a subsidiar intervenções para melhoria da assistência à população. Por essa razão o serviço também acolhe estudantes de pós-graduação, existindo, hoje, quatro alunos médicos do Programa de Pós-graduação em Obstetrícia e uma psicóloga do Programa de Pós-graduação em Medicina Preventiva desenvolvendo projetos de pesquisa, quatro em nível de mestrado e um de doutorado. Também estão sendo desenvolvidos cinco projetos de iniciação científica, por alunos de medicina 
e enfermagem, contribuindo para disseminar a proposta de abordagem integral às mulheres que sofrem violência sexual.

\section{Conclusões}

É postulado que o ensino, a pesquisa e a assistência à população devem se constituir nos pilares de atuação da Universidade. Para um correto desempenho dessa atribuição é necessário que a universidade esteja continuamente aberta à incorporação de novas demandas e desafios.

O recente reconhecimento da violência sexual como um importante agravo à saúde e violação dos direitos das mulheres tem exigido uma rápida resposta dos serviços e também do aparelho formador.

Ao mesmo tempo, as discussões sobre a integralidade no atendimento à saúde e a impor- tância da equipe interdisciplinar como tentativa de construção dessa perspectiva também se constituem em desafios atuais não apenas para quem presta o serviço, mas fundamentalmente para quem forma o profissional que irá prestar o serviço.

Nesse sentido, a criação de um serviço de atendimento a mulheres vítimas de violência sexual dentro de um modelo multidisciplinar e interdepartamental reafirma o compromisso da universidade pública com as demandas emergentes em saúde. A qualidade do atendimento, atestado pela grande adesão da clientela atendida, o interesse dos alunos de graduação e de pós-graduação, a possibilidade de servir como centro de sensibilização e capacitação dentro da área da saúde, indicam que a participação da Universidade é necessária e útil na abordagem da violência e que outros serviços semelhantes devem ser estabelecidos.

\section{Resumo}

Este artigo tem como objetivo discutir a importância da assistência multiprofissional às vítimas da violência sexual para redução dos agravos físicos, psíquicos e sociais que podem advir desta violência. Para tanto se faz uma breve descrição das atividades realizadas pelos diferentes profissionais que prestam assistência na Casa de Saúde da Mulher Professor Domingos Deláscio da Universidade Federal de São Paulo, e são apresentados alguns dos resultados deste trabalho nos seus cinco anos de existência. O artigo traça o perfil sócio-demográfico das mulheres vítimas de estupros que foram atendidas desde o início do serviço, detalhando quantas engravidaram e fizeram o aborto e o número de processos judiciais que foram abertos.

Violência Sexual; Estupro; Violência Contra a Mulher; Assistência

\section{Colaboradores}

Todos os colaboradores participaram do processo de elaboração do artigo. 


\section{Referências}

1. Andalaft Neto J, Mattar R, Colás OR. Violência sexual contra a mulher. Jornal da SOGESP 1999; 6: 39-40.

2. Oliveira EM, Barbosa RM, Moura AA, von Kossel K, Botelho LF, Stoianov M. Atendimento às mulheres vítimas de violência sexual: um estudo qualitativo. Rev Saúde Pública 2005; 39:376-82.

3. Faundes A, Hardy E, Osis MJ, Duarte G. O risco para queixas ginecológicas e disfunções sexuais segundo história de violência sexual. Rev Bras Ginecol Obstet 2000; 22:153-7.

4. Herbst M, Galvano A, Zeiguer N, Tiberti P, Bignes A, Machado O, et al. Hallazgos en niñas y púberes sexualmente abusadas. Rev Soc Argent Ginecol Infanto Juvenil 1999; 6:3-14.

5. Hamptom HL. Care of the woman who has been raped. N Engl J Med 1995; 332:234-7.

6. Gostin LO, Lazzari Z, Alexander D, Brandt AM, Mayer KH, Silverman DC. HIV testing, counseling, and prophylaxis after sexual assault. JAMA 1994; 271:1436-44.
7. Jenny C, Hooton TM, Bowers A, Copass MK, Kriegeer JN, Hillier SL, et al. Sexually transmitted diseases in victims of rape. N Engl J Med 1990; 322:713-7.

8. Seedat S, Stein DJ, Carey PD. Post-traumatic stress disorder in women: epidemiological and treatment issues. CNS Drugs 2005; 19:411-27.

9. Ullman SE, Filipas HH, Townsend SM, Starzynski LL. Trauma exposure, posttraumatic stress disorder and problem drinking in sexual assault survivors. J Stud Alcohol 2005; 66:610-9.

10. Novaes DR. Revisitando as concepções de integralidade. Revista de APS 2006; 9:1-16.

11. Ministério da Saúde. Norma técnica prevenção e tratamento dos agravos resultantes da violência sexual contra mulheres e adolescentes. 2a Ed. Brasília: Ministério da Saúde; 2002.

Recebido em 31/Ago/2006

Aprovado em 06/Set/2006 